\title{
Using 3-dimensional printing technology to deliver patient-centered care
}

\author{
Lisa M. Brown, MD, MAS
}

\footnotetext{
From the Division of Cardiothoracic Surgery, Department of Surgery, University of California Davis Health, Sacramento, Calif.

Disclosures: Author has nothing to disclose with regard to commercial support.

Received for publication July 4, 2018; accepted for publication July 6, 2018; available ahead of print Aug 11, 2018.

Address for reprints: Lisa M. Brown, MD, MAS, Division of Cardiothoracic Surgery, Department of Surgery, University of California Davis Health, 2221 Stockton Blvd, Rm 2115, Sacramento, CA 95817 (E-mail: lmbrown@ ucdavis.edu).

J Thorac Cardiovasc Surg 2018;156:2022

$0022-5223 / \$ 36.00$

Copyright (c) 2018 by The American Association for Thoracic Surgery

https://doi.org/10.1016/j.jtcvs.2018.07.009
}

Patients with tracheobronchomalacia and other airway disorders experience weakening of the central airway walls leading to excessive dynamic airway collapse (EDAC) upon exhalation. ${ }^{1}$ EDAC has a significant influence on quality of life, with dyspnea on exertion being the primary symptom for those whose disease is severe enough to warrant stenting and possible tracheobronchoplasty. ${ }^{1}$ Diagnosis of EDAC is via computed tomography scanning or visualization of airway collapse on bronchoscopy with forced expiratory maneuvers. ${ }^{2}$ The goals of treatment are to ensure mucociliary clearance, improve expiratory airflow, and restore airway patency. ${ }^{2}$ Airway stents are used primarily as a trial therapy to predict whether a patient will benefit from tracheobronchoplasty. ${ }^{2}$ At 1 high volume center, $60 \%$ to $75 \%$ of patients with central airway collapse have improvement in symptoms after stent placement, and of those $80 \%$ will benefit from tracheobronchoplasty. ${ }^{3}$ Unfortunately, not all who undergo tracheobronchoplasty have long-term relief of symptoms. Moreover, not all patients with EDAC are able to undergo tracheobronchoplasty.

Schweiger and colleagues ${ }^{4}$ describe the use of patientspecific silicone $Y$-stents engineered via 3 -dimensional technology in 2 patients with recurrent EDAC after tracheobronchoplasty. Complications and side effects of stent placement include mucus accumulation within the stent and between the airway and the stent as well as formation of granulation tissue and stent migration. For these reasons, stents are typically not used for long-term airway stabilization. Silicone $Y$-shaped stents and uncovered, self-expanding metallic stents can be used. ${ }^{2}$ However,

\section{References} 2010;22:165-73. 2017;9:E57-66.

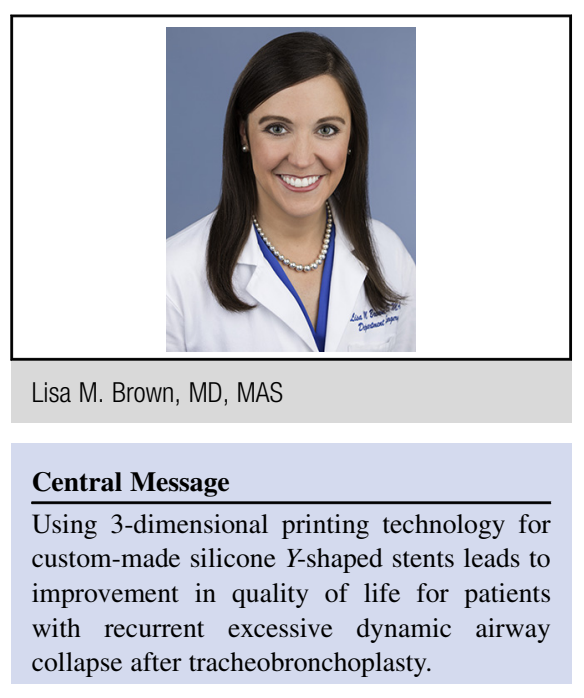

See Article page 2019.

long-term use of metallic stents should be avoided in patients with benign disease because of fracture, migration, granulation tissue, stenosis, and infection. ${ }^{2}$ Silicone $Y$-shaped stents are preferred but are prone to mucus plugging and may lead to intractable coughing. ${ }^{2}$ By using custom-made silicone $Y$-shaped stents, the 2 patients presented by Schweiger and colleagues ${ }^{4}$ experienced a significant improvement in quality of life at 5 and 8 months after stenting. This patient-centered approach was made possible by the use of 3-dimensional printing technology.

1. Gangadharan SP. Tracheobronchomalacia in adults. Semin Thorac Cardiovasc

2. Parikh M, Wilson J, Majid A, Gangadharan S. Airway stenting in excessive central airway collapse. J Vis Surg. 2017;3:172.

3. Buitrago DH, Wilson JL, Parikh M, Majid A, Gangadharan SP. Current concepts in severe adult tracheobronchomalacia: evaluation and treatment. J Thorac Dis.

4. Schweiger T, Gildea TR, Prosch H, Lang G, Klepetko W, Hoetzenecker K, et al. Patient-specific, 3-dimensionally engineered silicone Y-stents in tracheobronchomalacia: clinical experience with a novel type of airway stent. J Thorac Cardiovasc Surg. 2018;156:2019-21. 